\title{
CONTRIBUCIONES AL ESTUDIO DEL FILOHELENISMO EN HISPANOAMERICA: CANTOS A LA GRECIA LIBRE EN LA GRAN COLOMBIA
}

\author{
Eva Latorre Broto \\ Investigadora independiente
}

Resumen: En el presente artículo pretendemos llamar la atención de los investigadores sobre un aspecto inconcluso de nuestra tesis doctoral: la necesidad del estudio del filohelenismo en la Gran Colombia de Simón Bolívar a través de la prensa de la época, así como la localización de la publicación original de dos poemas filohelénicos cuyos autores fueron actores imprescindibles en el proceso colombiano de construcción nacional.

Palabras clave: Filohelenismo - Revolución Griega - Simón Bolívar - José Fernández Madrid - José María Salazar - Prensa hispanoamericana del s. XIX.

\section{CONTRIBUTIONS TO THE STUDY OF PHILHELLENISM IN LATIN AMERICA: SONGS TO FREE GREECE IN THE GREAT COLOMBIA}

\begin{abstract}
This article aims to draw the attention of researchers to an undeveloped aspect of our Ph. D. thesis: the need to study Philhellenism in Simón Bolívar's Gran Colombia through contemporary press, and besides to locate the original publication of two philhellenic poems by authors who played an essential role in the process of Colombian nation-building.
\end{abstract}

Keywords: Philhellenism - Greek Revolution - Simón Bolívar - José Fernández Madrid - José María Salazar - Press in 19th-century Latin American.

Recibido: 14.12.2019 - Aceptado: 31.05.2020

Correspondencia: Eva Latorre Broto

Email: elatorre.academia@gmail.com Investigadora independiente.

ID Orcid: https://orcid.org/0000-0002-6841-0925 


\section{El estudio del filohelenismo en el ámbito hispánico.}

71 filohelenismo, no ya en su sentido literal de "amor a Grecia $\checkmark$ y a lo griego", sino en su acepción política de defensa de Grecia como nación independiente, ha sido objeto de una nutrida bibliografía ${ }^{1}$. Desde el instante en que Aléxandros Ipsilandis se rebeló contra la autoridad del Imperio Otomano en los Principados del Danubio en marzo de 1821, la cuestión griega hizo correr ríos de tinta en las prensas de la Europa de la Restauración. Superada la duda inicial sobre la conveniencia de apoyar una insurrección que en aquella coyuntura se interpretó como una más de las revoluciones surgidas al albur de la instauración del sistema constitucional en España en enero de 1820, la intervención aliada de Gran Bretaña, Francia y Rusia en la batalla de Navarino en octubre de 1827 hizo posible al fin la independencia de Grecia.

La historiografía internacional ha investigado en detalle la contribución a este triunfo tanto de las tres potencias que tuvieron un papel decisivo en la emancipación de Grecia como la de otros países europeos, sobre todo Italia y Alemania, e incluso los Estados Unidos de América. Una parte fundamental de esta investigación ha consistido en la recopilación del mayor número posible de testimonios artísticos, literarios y políticos de tema filohelénico con el fin de evidenciar la profunda repercusión que la lucha griega tuvo entre la opinión pública internacional de la época y legitimar así la intervención de los gabinetes europeos en los asuntos de Grecia $^{2}$.

Quizá porque las circunstancias impidieron que ni desde España ni Hispanoamérica se realizara ninguna aportación material de relevancia a la lucha griega, el ámbito hispánico no ha gozado de la misma sistematicidad y exhaustividad. Descuidando etapas como el Trienio Liberal (1820-1823)

1 Para una sugestiva reflexión sobre el surgimiento del filohelenismo decimonónico de trascendencia política a partir del helenismo erudito dieciochesco, v. Zanou (2015); Tolias (2017) elabora el relato del filohelenismo desde la Antigüedad hasta finales del s. XIX, ofreciendo un completo repertorio bibliográfico.

2 Ya en 1974 la investigadora griega Loukia Droulia llevó a cabo el inventario de todas las obras conocidas hasta entonces de tema filohelénico, del que se ha editado una segunda versión revisada y considerablemente aumentada, v. Droulia (2017). 
y el exilio liberal durante la Década Ominosa (1823-1833), el estudio del filohelenismo en España se ha centrado en las obras sobre la Revolución Griega — ensayos, novelas y poemas - que comenzaron a aparecer sobre todo a partir de 1828, cuando la libertad de Grecia ya era un hecho.

En cuanto al espacio americano, aunque ya en su momento se habían establecido similitudes entre la Grecia bajo el poder de la Sublime Puerta y la América sometida a la Corona española, el análisis de las manifestaciones del filohelenismo en Hispanoamérica ha carecido de esa concentración temporal y espacial que permitía la península, presentando hasta hace muy poco trabajos y menciones, si bien muy sugerentes, dispersos y $\sin$ continuidad ${ }^{3}$.

Ante este vacío, el primer objetivo de nuestra tesis doctoral Filohelenismos hispánicos. Lo griego como referente de autorrepresentación en los discursos ideológicos de España e Hispanoamérica (1821-1824) fue cubrir los espacios y los tiempos desatendidos por los filohelenistas. Partiendo de la premisa de que su simultaneidad con los inicios de la Revolución Griega nos permitiría extraer un relato en tiempo real de la recepción de los sucesos de Oriente por parte de la sociedad española, decidimos centrarnos en el Trienio Liberal, lo que nos llevó a incluir a América en nuestro horizonte de estudio, pues en 1821 las grandes potencias aún no habían reconocido la independencia de las nuevas repúblicas, de modo que, técnicamente, aún seguían siendo España.

Dado que nuestro propósito era reconstruir el impacto de la Revolución Griega en las opiniones públicas del ámbito hispánico, la

3 Importante a este respecto es Vrai Système de l'Europe relativement à l'Amérique et à la Grèce par M. de Pradt, Paris, 1825, traducida en ese mismo año al español para su difusión en América. Por otra parte, hasta donde sabemos, el primer estudio moderno sobre Grecia e Hispanoamérica es G. Stadtmüller, "Paralelos y relaciones entre la revolución emancipadora de Latinoamérica y el filohelenismo", Congreso de Academias de Institutos Históricos sobre el pensamiento constitucional de Latinoamérica (1810-1830). Sesquicentenario de la Independencia de Venezuela, Caracas 1962, v. II, 154-155. El autor publicó después "Die lateinamerikanische und die griechische Unabhängigkeitsbewegung. Ein historischer Vergleich", Saeculum 33 (1982), 74-87. Por citar algunos estudios muy interesantes, Suárez (1984), Taboada (2008), y Miranda (2018). Mención aparte merecen los numerosos trabajos en los que el profesor Miguel Castillo Didier ha trabajado en paralelo las figuras de los precursores Rigas de Velestino y Francisco de Miranda. 
prensa debía ser la fuente de información principal. Los materiales a nuestra disposición para estudiar el surgimiento del sentimiento filohelénico en la península fueron tan abundantes que pudimos incluso definir matices entre los filohelenismos expresados por las distintas corrientes ideológicas del Trienio, pero no ocurrió lo mismo a la hora de explorar el filohelenismo en el ámbito americano, ya que las fuentes documentales se encontraban muy lejos de nuestro alcance. No obstante, y gracias a las herramientas de búsqueda en bibliotecas digitales, aún pudimos localizar textos suficientes como para atrevernos a trazar al menos unas líneas generales que pudieran servir a estudios ulteriores sobre el significativo eco que la insurrección griega tuvo en la América española.

De entre todo el corpus documental recopilado con tema central o mención a la Revolución Griega, destacaban poderosamente las piezas poéticas. En su doble condición de poemas publicados en prensa, presentaban un valor añadido mayor que otros textos en prosa según los postulados de la crítica literaria y de la historiografía, disciplinas que defienden el papel determinante que la poesía patriótica y la prensa desempeñaron, respectivamente, tanto en la ilustración política del pueblo y la expresión de sus aspiraciones colectivas, como en la creación de la opinión pública y de la conciencia ciudadana en los nuevos entornos de sociabilidad que abría la ideología liberal ${ }^{4}$.

Algunos de estos poemas ya habían sido tratados por la crítica, pero bien por haber sido considerados desde el punto de vista de la tradición clásica o del neoclasicismo de herencia colonial, bien por haber sido tratados desde el romanticismo orientalista, su contenido filohelénico quedaba un tanto eclipsado. Prescindiendo de valoraciones estéticas sobre los poemas, nuestro análisis se centró en su contenido ideológico, pues al haber sido publicados en la prensa de sus respectivos países, cada uno de ellos es un testimonio directo tanto de lo que los intelectuales querían que la ciudadanía leyera, como de las informaciones que la opinión pública en gestación estaba interesada en leer.

La conclusión que se podía extraer de la lectura de esos poemas era clara: mientras que en los poemas filohelénicos publicados en la península durante el Trienio Liberal la lucha de Grecia contra el Imperio Otomano

$4 \quad$ La bibliografía a este respecto es tan abundante que resulta inabarcable. Baste citar aquí el clásico F.-X. Guerra, Modernidad e Independencias. Ensayos sobre las revoluciones hispánicas. México: FCE, 1993. 
es utilizada como el paradigma de la lucha entre libertad y despotismo, esto es, las dos formas de concebir el gobierno político de la nación, el denominador común de la poesía filohelénica americana es la exaltación de la victoria de la libertad de la patria frente a un imperio invasor, esto es, el Imperio Español.

\section{Poesía filohelénica en la prensa hispanoamericana.}

Aunque en Hispanoamérica aparecen muestras de poesía filohelénica a lo largo de todo el siglo XIX, en el presente trabajo nos centraremos en los años del Trienio Liberal en la península, ya que coincidieron con el momento en el que las nuevas identidades nacionales americanas se encontraban en pleno proceso de construcción y la poesía, en su calidad de herramienta para la ilustración y cohesión de sentimientos nacionales, podía considerarse incluso como un crónica de actualidad ${ }^{5}$. Hasta el momento, en ese periodo, sólo hemos localizado muestras de poesía filohelénica en Argentina, Perú y Cuba, todas publicadas en prensa, y en cada uno de esos espacios la Grecia rebelde es utilizada como modelo de prestigio y adaptada a las peculiaridades de sus respectivos discursos fundacionales.

En Argentina, el Himno a la Grecia, publicado el 15 de mayo de 1822 en La Abeja Argentina, nos permitió reconstruir el ambiente del círculo de intelectuales de la Sociedad Literaria de Buenos Aires que, reunidos en torno a Bernardino Rivadavia, fundaron una patria sobre los principios republicanos de la Revolución Francesa y de la educación para la ciudadanía. La lucha de Grecia contra el opresor otomano para recuperar su antigua libertad y esplendor se consideró gemela de la propia contra el opresor español, cuya definitiva derrota y expulsión permitiría una América libre e ilustrada en la que Buenos Aires se alzaría como la Atenas del hemisferio Sur.

El poema La Grecia, publicado en el Correo Mercantil PolíticoLiterario de Lima el 23 de junio de 1822, es la pista principal para rastrear la intensidad que en Perú presenta la connotación de renacimiento implícita

5 En Latorre (2015) publicamos toda la poesía filohelénica escrita en español que hasta entonces habíamos logrado reunir, 35 piezas. La colección cierra en 1843 con el soneto dedicado a la Grecia libre, donde Gabriel de la Concepción Valdés, Plácido, lamentaba que otros países estuvieran aún bajo el yugo de la tiranía, en una alusión a su patria Cuba que resulta transparente para el lector. 
en la lucha griega, pues la reivindicación del Imperio Inca se estableció como uno de los elementos legitimadores del nuevo discurso nacional, tanto con el general José de San Martín como bajo el mando de Simón Bolívar. En Grecia, la voz fragorosa de los escenarios donde se consiguieron las más grandes victorias - Salamina, Maratón, las Termópilas - exige a sus sucesores gloria, libertad y venganza, de la misma manera que los genios tutelares incas claman victoria y venganza contra el español que los destruyó.

El caso de Cuba presenta un especial interés. La Oda a la insurrección de la Grecia en 1820 (sic), publicada en El Revisor Político y Literario de La Habana el 6 de agosto de 1823, es el primer poema filohelénico escrito en español con nombre expreso de autor. José María Heredia dio a la luz su extenso canto a la Grecia en armas, que finalizaba con la imagen de una Cuba risueña y coronada de palmas viendo "tan glorioso ejemplo", apenas una semana antes de la fecha fijada para la insurrección por la Sociedad Secreta de los Rayos y Soles de Bolívar con el gobierno español de la isla, en la que el poeta estaba implicado y cuyo fracaso le costó el destierro de por vida. El hecho de que Cuba sea el país de Hispanoamérica en el que, hasta ahora, se haya localizado el mayor número de poemas en los que se exalta la libertad de Grecia, quizá se deba precisamente a su condición de excepción americana por no haber podido conseguir, junto con Puerto Rico, la independencia de España al mismo tiempo que lo hizo la América continental $^{6}$.

\section{Poemas filohelénicos en la Gran Colombia.}

Muy a nuestro pesar, el capítulo sobre la recepción de la Revolución Griega en la Gran Colombia fundada por Simón Bolívar a raíz del Congreso de Angostura iniciado en 1819 es el gran ausente de nuestro estudio, y no por falta de poemas, sino por nuestra imposibilidad de acceder a la prensa colombiana de la época para localizar su publicación primigenia y

6 En la segunda parte de Latorre (2019), dedicada a Hispanoamérica, reeditamos estos poemas y estudiamos en detalle estos tres casos, cuya interpretación ofrecemos aquí de forma necesariamente sucinta, acompañados de un corpus documental tomado de las publicaciones de la época y de su correspondiente bibliografía. Incluimos un epílogo sobre poesía filohelénica en México en 1826 en el que se tratan las actividades de Heredia durante su exilio allí, $c f$. también Latorre (2013). 
poder así reconstruir el momento político, cultural y social en el que fueron transmitidos al público. Los poemas encontrados corresponden nada menos que a dos próceres de la patria colombiana, ambos íntimos colaboradores de Simón Bolívar: José Fernández Madrid y José María Salazar.

\section{3.a) José Fernández Madrid: Oda a los pueblos de Europa (1824).}

Dado el importante papel desempeñado por José Fernández Madrid en los procesos revolucionarios de Nueva Granada y de Cuba, y su servicio a Bolívar, sus actividades políticas y su producción científica y literaria han sido muy estudiadas ${ }^{7}$. Aquí nos detendremos sólo en aquellos aspectos de su vida que nos conduzcan directamente a la Oda que nos interesa.

Nacido en Cartagena de Indias el año 1789 en el seno de una familia de rancia aristocracia criolla, José Luis Fernández Madrid y Fernández de Castro se doctoró en Derecho y Medicina en Santa Fe de Bogotá antes de cumplir los veinte años, y ya publicó sus primeras poesías en El Argos y El Alternativo del Redactor Americano como miembro de la tertulia del Buen Gusto.

Desde el primer momento se implicó en la formación del aparato político que sustituyó a la autoridad virreinal española en Cartagena, y el 10 de noviembre de 1811 firmó el Acta de Independencia de la Nueva Granada. Defendió a Bolívar cuando se dudaba si confiarle la conquista de Santa Fe de Bogotá en 1814, lo que hizo nacer una estrecha amistad personal entre ambos.

Fernández Madrid vivió de cerca las luchas intestinas de la nueva nación que provocaron la marcha de Bolívar a Jamaica. Cuando en abril de 1816 el general Pablo Morillo abordó la reconquista de la región, Madrid asumió la presidencia de una república que ya nadie quería defender y, junto con su familia y las escasas tropas que reunió, se internó en la selva para organizar una defensa imposible. Al caer prisionero de los ejércitos realistas, dirigió una súplica por escrito a Morillo en la que manifestaba su fidelidad a Fernando VII. Salvó su vida y la de su familia, pero esta rendición mancillaría por siempre su imagen de patriota, obligándole a justificarse en varias ocasiones por lo que fue una reacción de supervivencia a la desesperada.

7 Por ejemplo, Martínez Silva (1889), Fdez. de Castro (1942), Solano (2014). 
Morillo le perdonó la vida, pero lo desterró a España. El barco donde viajaban los prisioneros estaba en tan malas condiciones que apenas pudo llegar a Cuba. En La Habana, Madrid se ganó la confianza del Capitán General de la isla José Cienfuegos, enemigo de Morillo, quien se negó a enviarlo a España apelando a la importancia de su condición de médico. No tardó en ser reclamado por las clases acomodadas para el cuidado de su salud, lo que le permitió elaborar algunas memorias científicas que gozaron de gran éxito entre sus colegas y retomar a la vez sus inquietudes literarias ${ }^{8}$.

Cuando la Constitución se restauró en la península en 1820, Madrid no perdió tiempo en disfrutar de la libertad de prensa y en junio de ese mismo año refundó El Argos junto al argentino José Antonio Miralla. Entre sus opiniones políticas, de tono abiertamente secesionista, fue incluyendo sus Rosas, poemas inspirados por su esposa que se llegaron a considerar lascivos e incrementaron su fama aún más9. En 1822 recopiló su obra lírica en el primer volumen de sus Poesías —no llegó a publicar el segundo-, en cuya lista de suscriptores se da cita lo más granado de la sociedad habanera, y cultivó con gran éxito el teatro con tragedias como Atala, remedo de la obra de Chateaubriand, y Guatimoc, emperador azteca de cuyo asesinato se sirve para poner de relieve la crueldad y avaricia de los conquistadores españoles.

Aunque en la poesía política de Madrid, como su Oda a la restauración de la Constitución española o el Ditirambo a la memoria de Porlier y Lacy, se alaba a la España liberal, los ideales que trasluce son, en realidad, los de un patriota americano. Más allá de su labor periodística, entre 1822 y 1823 tuvo papel protagonista en la organización de la Sociedad Secreta de los Rayos y Soles de Bolívar, en la que ya se ha mencionado que se implicó también José María Heredia. Así lo recuerda Vicente Rocafuerte en sus Memorias:

8 Fdez. de Castro (1942a: 12-21). Sobre la repercusión de su labor profesional en la comunidad científica cubana, v. José Fernández Madrid y su obra en Cuba, 12-14.

9 Las Rosas han sido reeditadas por H. Orjuela en José Fernández Madrid. Lírica erótica, Bogotá 2001. 
"Había entonces en La Habana una sociedad muy secreta, que estaba en correspondencia activa con otra de Caracas y que presidía el mismo Dr. Fernández Madrid, muy conocido entre nosotros por sus virtudes, su distinguido talento y sincero patriotismo: él me hizo el favor de iniciarme en los misterios de esa patriótica asociación, y desde entonces quedamos estrechamente unidos por los vínculos de la más franca y tierna amistad"10.

La implicación de Madrid en la sociedad secreta bolivariana no pasó desapercibida para Francisco Dionisio Vives, el nuevo Capitán General de Cuba desde mediados de 1823. Con motivo del proceso judicial abierto contra los conspiradores, el 6 de septiembre dirige una carta a Tomás Gener, diputado cubano en Cortes junto con Félix Varela, en la que dice:

"Usted sabe muy bien que Miralla, Madrid y Tanco son el alma de la conspiración y que siempre han trabajado por la independencia [...] haciendo nacer desconfianzas que debilitan y desacreditan a la Autoridad; Madrid y Miralla, sabe Vd. la parte activa que tuvieron en las ocurrencias de las paradas, sucesos que quedaron dormidos como sucedería con la causa actual, si hubiera conocido uno de los Jueces de Letras" $"$.

Heredia fue delatado y se ocultó de las autoridades hasta que al final se vio obligado a escapar clandestinamente rumbo a Boston, pero Madrid no fue citado en las actas del proceso. Se refugió en su profesión mientras ayudaba a huir a numerosos proscritos, quizá también al propio Heredia, y desahogaba su ira escribiendo poemas como su Canción con motivo del restablecimiento del poder absoluto en La Habana en 1823, y su Oda a los pueblos de Europa. 1824, que el estudioso Juan Antonio Fernández de Castro califica de

$10 \quad$ Apud Fdez. de Castro (1942a: 24-25).

11 Fdez. de Castro (1942 $2^{\text {b }}$ 43-44), reproduce el texto completo de la carta. 
"Versos viriles, [...] tan llena de justificadas arrogancias esperando aún en el triunfo de la Libertad, cuando todo parecía cerrársele, no sólo el horizonte político, sino el puramente personal" ${ }^{\prime 2}$.

Al igual que Heredia un año atrás, Fernández Madrid vuelve a cantar a la Grecia en armas como la musa capaz de impartir lecciones de libertad gracias a su abnegación y a su coraje, y esta vez no sólo a Cuba, sino a la Europa entera, subyugada de nuevo por el despotismo:

“¿Dónde los esforzados?

¿Los libres dónde están? ¿Cómo pudieron

Rehusar el combate intimidados?

¡Ay de los miserables que cedieron

El campo sin morir, al extranjero!"13

Aunque sus circunstancias lo obliguen a cantar en secreto en su alcoba de exiliado, la voz poética es la de un americano que se siente autorizado a hacer ostentación de libertad, porque la mayor parte de América ya es libre. América nada tiene que envidiar a unos refinados oropeles que sólo esconden "un abismo de servidumbre, lágrimas y horrores" en una "Europa esclavizada" que da todo a sus Reyes y a sus Pueblos nada (vv. 13-30). En este escenario de terror tan sólo es digno de elogio el monarca británico por no haber extendido "la noble mano fuerte y generosa" a una "liga inicua y tenebrosa" (vv. 31-36) - la Santa Alianza, aunque no la menciona de forma expresa en el poema-. Continúa el poeta recordando las atrocidades del despotismo - un gigante de pies de barro-, y recrimina a Francia el haberse unido a los bárbaros (vv. 3774), para exhortar a España, a Portugal e Italia (vv. 75-110) a que miren hacia Grecia, que ha logrado renacer y destrozar la media luna alzándose al llamado de guerra de la patria (vv. 111-116). Cierra el poema el recuerdo de lord Byron, el "Cisne de Albión" que muere cantando e implorando al Cielo en favor de la Grecia (vv. 117-123).

Si como reza el título, la oda fue escrita en 1824 - un término post quem es la muerte de lord Byron y el tiempo que tardara en llegar la noticia al Caribe-, Madrid se hallaba todavía en Cuba intentando pasar

$12 \quad$ Fdez. de Castro (1942 $2^{\text {b }}$ 47-48).

13 JFM, Poesías 1828, 40-44. V. también Latorre (2019 II: 374-375). 
desapercibido. A principios de 1825 escapó a Colombia, que Bolívar ya había convertido en la Gran Colombia, sin que hayan trascendido los detalles de su viaje.

En cuanto regresó a Cartagena, desde algunos folletos y periódicos, como El Noticiozote, se le recordó su episodio con Morillo - a veces con sorna, a veces acusándole de cobarde y traidor-, y Madrid debió defender su reacción en aquella difícil situación, ya desde cabeceras como El Constitucional, ya en folletos independientes. Su amigo Bolívar, sin embargo, nunca dudó de él, y el 25 de marzo de 1826 le nombró agente confidencial en Francia con el fin de conseguir el reconocimiento de la República de Colombia ${ }^{14}$. El 26 de agosto José Fernández Madrid envía su primer oficio diplomático desde París.

Su misión no era fácil; la estrecha relación política con España suponía una seria traba para que Francia pudiera obrar con libertad en lo tocante a ciertos negocios con América pero, en sólo un año, Madrid logró que los puertos franceses aceptaran el pabellón colombiano y que ambos Estados intercambiaran cónsules en lo que fue un reconocimiento implícito de su patria ${ }^{15}$. En París publicó su tragedia Guatimoc, que abrió con una devota dedicatoria para Simón Bolívar, y preparaba una nueva edición de su obra poética cuando recibió a José Joaquín de Olmedo, el poeta cantor de La victoria de Junín, que se encontraba en Londres como representante diplomático de Perú y visitó París entre finales de 1826 y mediados de 1827. Así lo contaba Olmedo a su amigo Andrés Bello, secretario de la legación de la Gran Colombia en Londres, en marzo de 1827:

\section{$[\ldots]$}

"Hoy he visto a Madrid; y como siempre, hemos hablado de usted.

Para dar a usted una idea del carácter de este amigo, bastará decir que tiene el candor y la bondad de darme sus versos para que se los corrija, y lo que es más raro, la docilidad de ceder a mis observaciones. $[\ldots]$

14 Fdez. de Castro (1942 ${ }^{\text {c: }}$ 8). Sobre la controversia por la actuación de Madrid ante las tropas de Morillo en 1816, v. Martínez Silva (1889: 126-129), Quijano (1917: 123-127), Triana (2005: 72-73), Solano (2014: 165-183). Sobre la construcción retórica e ideológica de su autodefensa, imprescindible Acevedo (2019).

Quijano (1917: 131-136) ofrece un extracto de sus oficios diplomáticos. 
Madrid está imprimiendo sus poesías; (aquí entre nosotros) lo siento. Sus versos tienen mérito, pero les falta mucha lima. [...] En una noche, de una sentada, traduce una Meseniana de Lavigne, o hace todo entero... el quinto acto de una tragedia" ${ }^{16}$.

Esta opinión de Olmedo sobre la poesía de Madrid ha hecho que la crítica fije su atención en la oda que nos ocupa, pues en la siguiente carta que dirige a Andrés Bello, Olmedo la considera no sólo la mejor de toda la producción de Madrid, sino mejor incluso que la suya propia. Bello, que había comenzado a editar El Repertorio Americano en Londres en octubre de 1826, debió pedirle algunos poemas a vuelta de correo, y Olmedo le responde:

"Usted es el demonio. ¡Pensar que yo puedo hacer versos ahora, y aquí, y pronto, y para el Repertorio! [...] Pero con el deseo de complacer a usted de algún modo, le propongo darle una composición muy superior a todo lo que yo puedo dar ni aun exprimido. Es una oda A los pueblos de Europa (1824), de ciento treinta versos en estrofas regulares, es buena composición de Madrid: la mejor de todas las suyas, en mi humilde opinión. Me ha permitido que se la ofrezca a usted, pero no debe llevar su nombre, porque, siendo un diplomático en Europa, sería muy mal visto que hablase de la Santa Alianza, de los reyes y de los pueblos, como habla en sus versos. Deberá, pues, salir firmada por "Un Colombiano. 1824".

Yo no debo ocultar a usted nada: esta composición es y no es inédita. No lo es, porque se imprimió en un periódico de Colombia, y lo es, porque la impresión en los diarios no se cuenta. Tan cierto es esto, que yo, que soy lector, y estaba en Colombia por aquel tiempo, no la he visto hasta ahora.

Hábleme usted con franqueza; porque la permisión del autor es en términos que no habrá nada perdido en caso de que usted tenga razones para no insertarla" 17 .

16 Epistolario de Olmedo, 268-269, de Olmedo a Bello, París 08/03/1827. Esta alusión a las Mesenianas sugiere que Madrid estaba interesado en poesía filohelénica.

17 Epistolario de Olmedo, 271, Olmedo a Bello, París 20/03/1827. Esta carta es reproducida en Epistolario de Bello, 260-261, si bien con una llamativa 
La reserva con la que Fernández Madrid cede su Oda a los pueblos de Europa muestra su plena conciencia de la carga de profundidad que todavía encerraban sus versos. En realidad, la situación política europea apenas había cambiado: la Santa Alianza seguía vigente y, aunque a principios de 1827 el filohelenismo ya había calado hondo en la sociedad, la postura oficial del gobierno francés fue reacia a apoyar a Grecia hasta que firmó junto con Gran Bretaña y Rusia el Tratado de Londres en ese mismo año. Aunque Madrid estaba lo bastante orgulloso de su oda como para seguir queriendo darla a la imprenta, debía moverse con discreción, ya que sus soberbias increpaciones poéticas podrían dar al traste con sus acciones diplomáticas y arruinar el futuro de su patria. La situación era tan delicada que el propio Madrid insiste en la prudencia con la que había que tratar este poema cuando se dirige por primera vez a Andrés Bello aún no se habían conocido personalmente- con motivo de los rumores sobre su nombramiento como responsable de la Legación colombiana en Londres, lo que le convertiría en jefe de Bello:

"Ya había yo leído y con mucho gusto El Repertorio Americano [...]. Procuraré remitir a V. los materiales que pueda yo adquirir. El Sr. Olmedo me dijo que iba a remitir a V. unos versos míos. En caso de que lo haya hecho, y de que Vd. resuelva insertarlos en El Repertorio, le suplico que no me nombre, pues hallándome negociando en esta corte, tal vez no sería prudencia"18.

El traslado a Londres se confirma, y el 30 de abril de 1827 ya escribe a Bello comunicándole su llegada allí. La relación entre ambos será excelente, sin embargo, en el siguiente volumen del Repertorio de agosto de 1827, que ya será el último, Bello no incluye la Oda a los pueblos de

\footnotetext{
variación, pues ofrece la lectura «Oda a los pueblos de Europa (1825) [...], "Un Colombiano" (1825)» en lugar de «1824» cuando Olmedo cita el nombre de la oda y el pie de firma que debería aparecer. Esto plantea un problema de crítica textual que sólo podría resolverse accediendo al documento original. Consideramos que el Epistolario de Olmedo tiene mayor credibilidad, pues 1824 es el año que figura en las Poesías que Madrid publicó en Londres en 1828, y también en la edición de esta carta que Martínez Silva incluye en la biografía del poeta, p. 366.
} 
Europa de Fernández Madrid, sino sólo una letrilla satírica a un amigo cubano $^{19}$. Resulta arriesgado afirmar que Bello no se atrevió a publicar esta comprometida oda, pero lo cierto es que si hubiera deseado hacerlo, habría tenido ocasión.

La Oda a los pueblos de Europa. 1824, salió por fin en letra de molde incluida en la segunda edición de sus Poesías que José Fernández Madrid pudo publicar en Londres en 1828, aquella que ya estaba preparando durante su estancia en París. Ante la prevención que Madrid demostró tener con esta oda cabe preguntarse: ¿habría sido incluida igualmente si hubiera editado sus Poesías en París? Debemos recordar que, aunque la visión de la Revolución Griega cambió después de la batalla de Navarino en octubre de 1827 hasta el punto de que Francia absorbió prácticamente todo el protagonismo de la victoria erigiéndose en la libertadora de Grecia, Carlos $\mathrm{X}$ seguiría en el poder hasta ser derrocado por Luis Felipe de Orleáns en julio de 1830, y el sistema despótico criticado en la Oda a los pueblos de Europa seguía todavía vigente.

Si bien esta oda todavía podía encerrar aromas de insurrección susceptibles de ofender a la vieja Europa, lo cierto es que no llamó la atención de sus contemporáneos americanos, entre los que Madrid fue muy admirado. En la reseña que José María Heredia hace de la edición de sus Poesías de 1828, al tiempo que recuerda la "amistad íntima y tierna, fundada en semejanza de ideas, opiniones y afectos" que los unió, dice de él que "supo entonar con felicidad la trompa de Tirteo, el laúd de Tibulo y la lira de Píndaro y de Pope", pero ni siquiera menciona esta oda, elogiando otros poemas de tono más lírico ${ }^{20}$. Por otra parte, tampoco aparece entre los poemas de Madrid incluidos en la antología El Parnaso granadino, que

19 M., “A Desval. Letrilla”, El Repertorio Americano IV, agosto de 1827, $10-11$.

20 "Poesías de José Fernández Madrid, Londres 1828", Miscelánea (Toluca), $2^{\mathrm{a}}$ época, I, $\mathrm{n}^{\mathrm{o}} 4$ (septiembre 1831), 114-123. La cita en p. 212. El poeta cubano siempre intentó difundir las poesías del colombiano a la par que declaraba la amistad que les había unido, como ya lo demostró al incluir $\mathrm{Al}$ Libertador, en su cumpleaños, en El Iris (México), II, no 20, 23/05/1826, 5356, con esta dedicatoria: "Si llegan estos renglones a manos de Madrid, sepa que en su Heredia no se ha entibiado la amistad que estrechó con él bajo los auspicios de un noble infortunio, y que hará eterna la armonía de sus principios e inclinaciones". 
se inclina por las poesías patrióticas dedicadas a Bolívar y por piezas más intimistas ${ }^{21}$.

Otros poetas posteriores llegarán a calificar a Madrid de "un sol que vino a alumbrar el suelo americano para gloria del mundo"; "profeta que con su lira de oro ha anunciado la redención de la América, y cuyos cantos son entonados por los ángeles tras el raso azul del firmamento", aunque ya en 1860, los hermanos Amunátegui se ocuparán de moderar tan encendidos entusiasmos:

"Fue un buen ciudadano que en una época crítica prestó servicios importantes a la patria. [...] Si tratáramos de honrar su memoria, nos encontraríamos dispuestos a hablar, no de las producciones del escritor, sino de las acciones del hombre"22.

Los dos hermanos desarrollan un estudio crítico de toda la obra de Madrid, pero la Oda a los pueblos de Europa sólo merecerá su atención para intentar atemperar los exabruptos contra los españoles con los que el poeta, miembro de la más rancia aristocracia criolla, expresa su patriotismo. Su odio no es contra todos los españoles, ya que él se declara español, sino contra todo enemigo de la libertad, pues en esta oda intentó inflamar el ánimo de España contra el despotismo, al igual que había hecho con América ${ }^{23}$.

Quizá el hecho de que esta oda sea la única en la que Madrid no irrumpe en denuestos contra España haya contribuido a su elección

21 El Parnaso granadino, por José Joaquín Ortiz, tomo I, Bogotá 1848.

22 Juicio crítico de las obras de algunos de los principales poetas hispanoamericanos. Memoria presentada por don Miguel L. y don Gregorio V. Amunátegui al certamen abierto en 1859 por la Facultad de Humanidades, y a la cual ésta, en sesión del 27 de julio de 1860, adjudicó el premio de la ley, en Anales de la Universidad de Chile 17 (agosto 1860), 756-775. La cita en 764. Los elogios a Madrid pertenecen a dos poemas dedicados al prócer colombiano por Santiago Pérez y José María Quijano, y publicados en Bogotá en 1851 y 1856, respectivamente, y recogidos por los Amunátegui en 756.

23 Ibidem, 770-771. Se refieren a los siguientes versos incluidos en la elegía La muerte de Atahualpa: «Sangre española corre por mis venas; / mío es su hablar, su religión la mía, todo menos su horrible tiranía», en JFM, Poesías $1828,11$. 
por parte de Marcelino Menéndez Pelayo para su Antología de poetas hispanoamericanos, a pesar de que en la introducción a su autor ni siquiera la menciona. La otra composición seleccionada es La hamaca, un divertimento ligero que es "casi lo único que sobrevive de sus versos"24. Menéndez Pelayo no salva a Madrid ni como patriota; al contrario, no duda en hacer sangre con su rendición ante Morillo, en la que ve el origen de lo que llama "miso-hispanismo frenético", un recurso del que el poeta se habría servido para echar tierra sobre aquella infamia. Ridiculiza también "el incienso que empalagosamente tributa al Libertador" y se muestra encantado de disponer de la opinión de los Amunátegui — dos críticos americanos premiados por la Universidad de Chile - para poder escudar en ella su escarnio del colombiano:

"Las odas políticas de Madrid son de la más intolerable y hueca patriotería, una sarta de denuestos en estilo de proclama. Los mismos críticos americanos han llegado a reconocerlo, y el Juicio de los hermanos Amunátegui, por duro que parezca, es en esta parte inapelable, y ha hundido para siempre al poeta cartagenero, astro de falsa luz, que sólo pudo deslumbrar un momento a los que equivocaban la verdadera grandeza con el énfasis bombástico" ${ }^{25}$.

Sin embargo, llama la atención un detalle: Fernández Madrid tituló su poema Oda a los pueblos de Europa. 1824, mientras que Menéndez Pelayo la titula A los pueblos de Europa en tiempo de la Santa Alianza. Desconocemos si este cambio de título responde a iniciativa propia o el polígrafo español lo tomó de alguna edición de las poesías de Fernández Madrid que nos ha sido imposible consultar ${ }^{26}$, pero en cualquier caso podemos afirmar con plena seguridad que, vista la cautela con la que

$24 \quad$ Menéndez Pelayo (1893 III: 11-18).

25 Menéndez Pelayo (1893 III: XXXVII) y (1913 II: 41-42).

26 Como, por ejemplo, la incluida en la edición canónica de sus obras: Obras de José Fernández Madrid. Reimpresas y publicadas en su centenario por la Gobernación del Departamento de Bolivir, Bogotá 1889. La mención de la Santa Alianza y la supresión del año («1824») en el título se mantienen en la reedición José Fernández Madrid, Poesías, Cartagena de Indias 1949, de la que www.cervantesvirtual.com ha digitalizado dos poemas, Napoleón en Santa Helena y Oda a los pueblos de Europa. 
su autor afrontaba en su época la publicación de esta oda, un título tan explícito y provocador jamás pudo salir de su pluma, pues incluso en América el poema circuló con el título Oda a los pueblos de Europa, como atestigua su edición en El Republicano de Buenos Aires el 16 de diciembre de 1831, bajo la firma "Un Sud-americano"27.

A lo largo del siglo $\mathrm{XX}$, la práctica totalidad de los críticos se han referido a este poema como el mejor de Madrid porque ésa era la opinión del incuestionado Olmedo ${ }^{28}$. Sin embargo, cuando en 1979 Emilio Carilla la recoja en su antología Poesía de la independencia, la Oda verá por fin reconocido el espíritu insurgente que marcó su génesis ${ }^{29}$. El juicio valorativo de Olmedo sobre su calidad literaria queda olvidado en pro de su carga política, y todos los estudiosos que traten la obra de Madrid a partir de Carilla harán alusión a ella como "encendidos versos revolucionarios" ${ }^{30}$. De Carilla la tomará también Hernán Taboada al hacer su exiguo pero pionero rastreo sobre la presencia de Grecia en la cultura de la independencia de América ${ }^{31}$.

No obstante, las palabras que Olmedo dedica a esta oda encierran un par de detalles en los que nadie parece haber reparado. Él habla a Bello de

"Una oda A los pueblos de Europa (1824), de ciento treinta versos en estrofas regulares [...]. Esta composición es y no es inédita. No lo es, porque se imprimió en un periódico de Colombia, y lo es, porque la impresión en los diarios no se cuenta. Tan cierto es esto, que yo, que soy lector, y estaba en Colombia por aquel tiempo, no la he visto hasta ahora".

27 Suárez (1984: 146-147). El autor menciona este poema como firmado por "Un Indoamericano" y tan sólo por su mención a Grecia, pero no lo relaciona con Fernández Madrid.

28 Ésta es la razón por la que Alberto Ghiraldo, por citar un ejemplo, lo incluye en su Antología americana. Lira heroica, Madrid 1923, 220-224.

29 Carilla (1979: 187-190).

$30 \quad$ V. gr., C. G. Méndez, "La azarosa vida de José Fernández de Madrid (biografía)", Boletín de la Academia de la Historia de Cartagena de Indias 167 (73) (abril 2000), 42-64; y L. M. Mendoza Vargas, Atala y la representación del Estado-Nación en el siglo XIX, Universidad Industrial de Santander, Bucaramanga 2008, 30.

31 Taboada (2008: 29). 
Pero, en primer lugar, el texto de esta oda que Fernández Madrid publicó en la segunda edición de sus Poesías en Londres en $1828-\mathrm{y}$ del que han bebido todas las reproducciones posteriores que han estado a nuestro alcance, aparezca o no la alusión a la Santa Alianza en los títulos que las encabezan - consta de ciento veintitrés versos y no de ciento treinta. En segundo lugar, si bien están distribuidos también en diez estrofas, éstas no son regulares, pues mientras la estructura general de todas ellas es de 12 versos, la sexta presenta 14 versos (vv. 61-74), y la décima presenta 13 (vv. 111-123); esto es, la versión conservada de esta oda no coincide en su forma con aquella descrita por Olmedo, la que había sido publicada "en un periódico de Colombia” y que probablemente constara de trece décimas, la única combinación estrófica regular en la que podemos organizar un total de ciento treinta versos.

Es evidente que Madrid reescribió esta oda para su publicación en Londres, dándole una nueva estructura y eliminando al menos siete versos, por lo que cabe preguntarse a qué se debe esta supresión: ¿fue a causa de "la lima" que Olmedo y Bello aplicaron a los versos de su amigo ${ }^{32}$, o fue que esos versos suprimidos tenían un contenido tan revolucionario que Madrid no se atrevió a darlos a la luz ni siquiera en la tolerante Gran Bretaña? La tercera estrofa, en la que alaba la decisión del generoso y noble monarca británico de no haberse unido a la tenebrosa Santa Alianza, así como el poético final en el que menciona la muerte de lord Byron, ¿se encontraban ya en la versión original, como homenaje a Gran Bretaña por haber sido la primera en reconocer la soberanía de Colombia ${ }^{33}$, o fueron añadidos a esa refección hecha en Londres con el fin de intentar agradar a la potencia ante la cual representaba a su patria como diplomático?

La constatación de que esta oda, a la que Fernández Madrid daba tanta importancia y trataba con tanta cautela, fue reescrita para su publicación en Londres abre una enorme cantidad de interrogantes que sólo podrán

32 El testimonio epistolar de Olmedo queda confirmado por el propio Madrid cuando en el prefacio de su edición londinense reconoce la intervención de Olmedo y Bello en la mejora de sus piezas poéticas: "Conozco sus defectos, que serían más numerosos si no hubiese corregido muchos de ellos con arreglo a las indicaciones que tuvieron la bondad de hacerme mis amigos los señores Olmedo y Bello", JFM, Poesías 1828, III.

33 En la Gaceta de Colombia del 04/03/1825, esto es, recién llegado Madrid a Cartagena, se transmite con gran alborozo la noticia de este reconocimiento. 
ser respondidos con la localización en la prensa colombiana de la época del texto primigenio. Esta investigación debería partir de unas acotaciones mínimas de tiempo y lugar. Sabemos que Madrid llegó a Cartagena de Indias en febrero de 1825 y que allí publicó al menos dos poemas en folletos independientes: Al padre de Colombia y Libertador del Perú, y Elegías nacionales peruanas. Hacia fines de junio de ese mismo año ya se encontraba en Bogotá, pues en El Constitucional del 7 de julio, periódico regentado por su amigo Miralla y un hijo del precursor Miranda, insertó un aviso en el que se defendía de su conducta ante Morillo y publicó su famosa Exposición de José Fernández Madrid a sus compatriotas sobre su conducta política desde el 14 de marzo de $1816^{34}$. Por otra parte, sabemos que Olmedo ya estaba en Londres en octubre de 1825, de manera que, si como él mismo afirma, aún se encontraba en Colombia cuando ese poema se publicó en un periódico, la horquilla cronológica en la que pudo aparecer la Oda a los pueblos de Europa abarca desde febrero de 1825 hasta, como mucho, finales de agosto o principios de septiembre de 1825. Dado además que Olmedo se encontraba en Bogotá, nos inclinamos a pensar que deberíamos empezar a buscar por la prensa capitalina de entre julio y septiembre de 1825 antes de pasar a agotar la de Cartagena de Indias ampliando la horquilla a febrero de ese año, fecha del regreso de Madrid a su ciudad natal. Creemos que el rastreo debería iniciarse por $E l$ Constitucional, que siempre sirvió de púlpito a la defensa pública de José Fernández Madrid.

Al carecer de una referencia bibliográfica concreta, nos ha sido imposible realizar esta labor de localización desde España. Hemos buceado en las hemerotecas digitales y hojeado los títulos comprendidos en la horquilla cronológica propuesta, como la Gaceta de Colombia (Bogotá), el Aviso con notas (Bogotá), el Correo del Madalena (Cartagena), accesibles en la Biblioteca Virtual Luis Ángel Arango, o la Miscelánea (Bogotá), en archive.org, lamentablemente sin éxito. La prensa americana de la época, y en concreto la colombiana, presenta problemas como la dispersión de ejemplares por diversas instituciones, series incompletas por provenir de colecciones particulares, o pérdida de cabeceras muy influyentes en su momento, como El Universal, de las que no se conserva ni un número ${ }^{35}$. No

34 Martínez Silva (1889: 126-129).

35 Orlando (2004) presenta un completo análisis de las colecciones de prensa colombiana del siglo XIX conservadas en la actualidad, así como un 
obstante, confiamos en que iniciativas tan magníficas como la Hemeroteca Digital de la Biblioteca Nacional de Colombia contribuyan en un futuro a universalizar el acceso a esta preciada documentación.

La búsqueda debería ser sistemática y paciente, con una tenacidad movida por la conciencia de que, si llegara a encontrarse aquella primera versión de la Oda a los pueblos de Europa, 1824, tendríamos ante nuestros ojos el producto de la expresión espontánea de un poeta revolucionario que desde su exilio en la Cuba de nuevo tiranizada añoraba el coraje de la Grecia en armas, siempre maestra de libertad. La comparación de esa versión prístina de ciento treinta versos con la versión canónica, que presenta sólo ciento veintitrés, nos permitiría saber hasta qué punto los cambios introducidos son consecuencia de censuras ajenas en pro de una mera contención estilística, o son debidos a la autocensura política de un poeta rebelde devenido diplomático cuyo éxito personal en todos los ámbitos radicó en saber elegir en todo momento la palabra acertada para cada ocasión.

Precisamente es este buen hacer de José Fernández Madrid lo que otorga especial importancia a la localización de estos siete versos silenciados pues, en según qué circunstancias, y más cuando un simple poema puede hacer peligrar unas negociaciones de Estado a Estado al más alto nivel, aquello que se calla siempre suele encerrar mucho más interés que lo que se dice.

\section{3.b) José María Salazar: A la muerte de lord Byron. Elegía.}

Desde que José María Heredia publicara en agosto de 1823 su entusiasta canto a Grecia, debemos esperar toda la Década Ominosa para que sea citada en otro poema aparecido en Cuba. Hasta donde sabemos, la siguiente mención poética de la Grecia libre aparece en la Colección de Poesías arreglada por un aficionado a las Musas, publicada en dos volúmenes en La Habana en 1833. El aficionado era el impresor José Severino Boloña, quien reunió poemas de allegados, algunos propios y otros de sus poetas favoritos. Entre Bartolomé de Argensola, Manuel José Quintana y Juan Nicasio Gallego, encontramos autores cubanos como Manuel Zequeira, Ignacio Valdés Machuca (Desval) y Francisco Iturrondo

listado orientativo de las instituciones cuyos fondos pueden deparar sorpresas cuando sean catalogados y puestos a disposición del público. También Angulo (2008). 
(Delio). La Colección recoge piezas de circunstancia sobre episodios como la Batalla de Trafalgar y el 2 de Mayo en Madrid, y eventos como bodas y defunciones de la Familia Real, llegadas y partidas de capitanes generales y obispos a la isla, la introducción de la vacuna, loas a las bellezas de la tierra y otras piezas ligeras de carácter lírico y burlesco.

La nota discordante entre los trenos que lamentan la pérdida de próceres varios la encontramos en A la muerte del lord Byron (Jorge Gordon), acaecida el día 19 de abril de 1824. Elegía, firmada por las iniciales " $L$. P.", de 15 estrofas sáficas, muy habituales en el neoclasicismo español ${ }^{36}$. Retornadas las Musas a su cuna después de siglos de exilio por haber vencido "el patrio acero / las cimitarras y la media luna / del turco fiero", el poeta las invita a mostrar su dolor sobre la "tumba fría" ante la cual incluso los héroes "bajan las armas" como homenaje al que juró con ellos "libertad o muerte", quien "a la Grecia consagró atrevido / su brazo fuerte". El final del poema sorprende: es de justicia que las ninfas del Támesis alcen su canto de duelo, pues incluso una "musa que en el Funsa mora" canta el nombre de Byron. Una nota a pie de página indica que se alude a un "pequeño río de Bogotá".

En su intento por modernizar el panorama intelectual y literario de la isla, Domingo del Monte, referencia de la clase criolla cubana culta y adinerada, quien fue admirador de José Fernández Madrid mientras estuvo en La Habana y amigo íntimo de José María Heredia, introdujo a autores románticos como Walter Scott o lord Byron. Así, la presencia de esta elegía a Byron no resulta tan desconcertante como la alusión, llena de connotaciones en aquel contexto político, al río Funza, por cuyo cauce transcurrió buena parte de la ruta libertadora de Bolívar desde la victoria de Boyacá en 1819 hasta que arrebató Bogotá a los ejércitos realistas y en 1821 la convirtió en la capital de la Gran Colombia. De esta manera, la libertad de Grecia y la de América vuelven a vincularse gracias a musas que cantan al unísono a ambos lados del Atlántico. En la Cuba de 1833, donde la simple mención de Bolívar podía dar inicio a una pesquisa policial ${ }^{37}$, el

$36 \quad$ Colección de poesías arreglada por un aficionado a las Musas II, 170173. V. también Latorre (2015: 123-125).

37 García (2004: 299). En 1831 el sargento del Batallón de Pardos denunció a las autoridades que, en una reunión, un grupo de hombres y mujeres de color habían brindado "por Bolívar", lo que abrió un largo proceso judicial en el que al final se concluyó que estaban preparando una obra de teatro, y si bien se encontró 
camuflaje de esta elegía entre los restantes 230 poemas de oropel colonial que componen la Colección presenta un mérito indiscutible. ¿Quién fue el poeta que se atrevió a tal osadía? Aunque la Colección suele presentar los poemas firmados con iniciales, éstas son fácilmente atribuibles a poetas conocidos, y muchas de ellas se repiten. No ocurre lo mismo con "L. P.", que sólo firma esta elegía y que no nos ha sido posible identificar ni con el nombre ni con el pseudónimo de ningún escritor de ese entorno.

Algunos enigmas parecen encontrar respuesta cuando descubrimos que esta misma elegía se encuentra entre la obra de José María Salazar, quien, como Madrid, también fue hombre de confianza de Bolívar y embajador de la Gran Colombia en los Estados Unidos ${ }^{38}$. Decepcionado por la agitación en la que su patria se hallaba inmersa, marchó a París, donde murió en 1828. Años más tarde, sus hijos recopilaron sus escritos en La Colombiada o Colón, El amor a la Patria y otras poesías líricas, que vio la luz en Caracas en 1852.

La autoría de Salazar dota de lógica a la mención del Funza en la Elegía a Byron, pues el control de su cuenca resultó vital para el éxito de la campaña y para este soldado-poeta debía tener una significación muy especial. De hecho, sus ninfas aparecen en otro de sus poemas, La campaña de Bogotá, en el momento en el que los ejércitos del Libertador hacen su entrada en la ciudad:

"Tejen guirnaldas de clavel y rosa

Del claro Funza las hermosas ninfas

Para ceñir la frente de los bravos

Que enjugaron sus lágrimas divinas" ${ }^{39}$.

algún material comprometido, se llegó al convencimiento de que la denuncia había sido motivada por una revancha amorosa del sargento denunciante.

38 La muerte de Lord Byron. Elegía, en JMS, La Colombiada, 163-165. Como era de esperar, Menéndez Pelayo no tiene buena opinión sobre él, aunque aporta datos muy interesantes sobre su figura: fue autor del primer himno colombiano y también de El soliloquio de Eneas y El sacrificio de Idomeneo, dos de las primeras tragedias originales que se presentaron en el teatro de Bogotá; vd. (1893: III, XXIX-XXXI) y (1913: II, 35-36). V. Gómez Restrepo (1945: III, 271-276); y H. Orjuela, José María Salazar, patriarca de la poesía antioqueña: antología, Bogotá D. C. 2002. 
Precisamente por la íntima conexión que se establece entre las ninfas del Funza que aclamaron al Libertador de América y las que cantan al libertador de Grecia, la presencia de la Elegía en la Colección habanera de 1833 queda sin explicar. A pesar de que su primera edición conocida data de 1852 en La Colombiada, encontramos la Elegía publicada en el Florida Herald del 27 de noviembre de $1840^{40}$, lo que avala la hipótesis de que ya circuló en prensa de Costa Firme y entró en Cuba en alguna publicación que consiguió escabullirse a la censura entre 1824 — muerte de Byron-y 1833.

Las tres versiones de esta elegía localizadas hasta el momento presentan entre ellas leves variantes textuales que carecen de relevancia en cuanto a su contenido, pero que podrían resultar significativas para remontar el cauce de su transmisión textual, ya que algunas de ellas producen la impresión de que el poema fue memorizado y luego transcrito para la edición cubana.

¿Halló L. P. el poema de forma casual y lo hizo pasar por suyo? ¿Llegó a saber L.P. que el poema era original de Salazar? ¿Corresponden esas iniciales a un mal poeta cuyo nombre no llegó a trascender y que usurpó un poema ajeno por no tener versos de valor? O por el contrario: ¿quiso L. P. aprovechar la enorme acumulación de poemas inofensivos para infiltrar una elegía de indudable aroma insurgente pero cuyo mensaje entenderían sólo aquellos que lo tuvieran que entender? ¿Era alguien conocido que se escondió bajo iniciales ficticias en una apuesta arriesgada que afortunadamente salió bien? ¿Fue el editor Boloña consciente de esta carga o le pasó desapercibida cegado ante el relumbrón de lord Byron, el poeta que Domingo del Monte había puesto de moda en la isla? Tan sólo la identificación de la persona que se ocultó tras esas iniciales nos permitiría inclinarnos hacia una $u$ otra hipótesis.

No obstante, un rastreo por la prensa de Costa Firme podría acercarnos a la publicación primigenia de esta Elegía. Al igual que la Oda de Madrid, la Elegía de Salazar nos diría mucho de su contexto político y social en el caso afortunado de que aún se conserve el papel en el que vio la luz primera, y sería una pieza importante para la cimentación de un estudio sistemático y detallado sobre la recepción de la Revolución Griega en la Gran Colombia.

en 179.

40 State Library and Archives of Florida https://ufdc.ufl.edu/ UF00079918/00078/1x 


\section{Conclusiones.}

Aunque, curiosamente, no hace alusión a la Oda a los Pueblos de Europa, en un trabajo concienzudo a partir de fuentes inaccesibles para nosotros, como el Archivo General de la Nación de Bogotá, el profesor Daniel Gutiérrez Ardila ha estudiado en detalle la importancia que los agentes de Bolívar en Europa, entre ellos Fernández Madrid, otorgaban a las noticias sobre la situación de Grecia en sus despachos diplomáticos. Esto confirma el interés que en el pensamiento americano de la independencia despertó la Revolución Griega y su evolución, precisamente por la identificación que desde un principio y desde varios ámbitos se hizo de las revoluciones griega y americana como dos procesos paralelos e inevitables según las circunstancias que marcaban las tendencias políticas internacionales. Por otra parte, el investigador Luis Alfredo de la Peña Jiménez ha iniciado recientemente una serie de interesantísimos trabajos en los que estudia los paralelismos y diferencias principales entre las independencias de Colombia y Grecia, atendiendo a los procesos transnacionales de modernización de la cultura política durante la Era de las Revoluciones y transferencias de ideas en los marcos epistemológicos de la Historia Global y de la Histoire Croisée $^{41}$.

Estos trabajos constituyen un excelente punto de partida para el estudio del filohelenismo en la Gran Colombia, pues han construido el entorno idóneo que permita descender desde la macrohistoria teórica y el interés por Grecia expresado entre las esferas de poder, privadas y elitistas, hasta la recepción de la Revolución Griega por parte de la sociedad colombiana.

La prensa debe ser la herramienta principal para examinar cómo los ideólogos trasvasaron la Revolución Griega a la opinión pública de la Gran Colombia. A pesar de que a priori no esperamos encontrar informaciones directas desde el Mediterráneo oriental, tanto el examen de las fuentes que los periodistas utilizaron, como la selección de noticias que realizaron de entre la prensa extranjera y sus propios comentarios añadidos sobre la evolución de la cuestión griega, pueden aportar información muy valiosa para definir el sesgo que querían trasladar a la ciudadanía sobre este tema. Esto permitiría verificar si el filohelenismo, la admiración a la Grecia en armas, llegó a funcionar como un elemento más en la articulación de su discurso nacional, tal y como hemos comprobado ya que sucedió en 
Argentina, Cuba y Perú ${ }^{42}$. Desde luego, lo que tanto la Oda de Fernández Madrid como la Elegía de Salazar permiten aventurar es que la Grecia en armas se proyectó en Colombia como una nación hermana cuya libertad era irreversible por el mero hecho de haber comenzado a pelear por ella, y capaz, por tanto, como la propia Colombia, de dar lecciones de libertad a otras naciones sumidas aún en el despotismo.

En este estudio de la prensa no deben menospreciarse los poemas insertos en ella, pues rara vez son inocentes, encerrando en ellos mucho más contenido ideológico que divertimento estético. Como ya dijo Luis Monguió, "La poesía fue un arma en el arsenal de los libertadores" ${ }^{43}$.

REFERENCIAS BIBLIOGRÁFICAS (Los enlaces digitales han sido verificados el 27/01/2020).

ACEVEDO, R. E. (2019), “El lector en su contexto. La defensa de José Fernández Madrid frente a los testimonios y la escritura de la historia de Colombia, 1821-1830", Co-herencia 16, no 31 (julio - diciembre de 2019), 223-258. DOI: $10.17230 /$ co-herencia.16.31.7

ANGULO MÉNDEZ, S. M. (2008), "Colombian newspapers of the 19th century : treasures and memory", Newspapers collection management : printed and digital challenges: proceedings of the International Newspaper Conference, Santiago de Chile, April, 3-5, 2007. IFLA Publications, vol. 133. Santiago de Chile, 179-206.

42 En Latorre (2019 I: 596-598) ya observamos que en la Gaceta del Gobierno de Perú durante el protectorado de José de San Martín (julio 1821-septiembre 1822) Grecia tan sólo aparece citada en una ocasión, mientras que esta tendencia cambia de forma drástica durante el gobierno de Bolívar (septiembre 1823-enero 1827). La guerra griega comienza a gozar de protagonismo, no tanto por el espacio que se le dedica como por la calidad de estas inserciones, pues suelen ir acompañadas de reflexiones de los redactores que resultan de importancia primordial para conocer la visión que de ella se quería proyectar hacia la sociedad peruana desde el discurso oficial del gobierno. De verificarse en la Gran Colombia un tratamiento similar de la Revolución Griega, podríamos plantear no ya un estudio del filohelenismo en el ámbito colombiano, sino en el más amplio ámbito bolivariano.

43 "La poesía y la independencia, Perú 1808-1825", Literatura de la Emancipación Hispanoamericana y otros ensayos. Memoria del XV Congreso del Instituto de Literatura Iberoamericana, $2^{a}$ sesión en Lima (9-14 de agosto de 1971), 7-15. 
CARILlA, E. (1979), Poesía de la Independencia. Caracas: Biblioteca Ayacucho. CASTILLO-MIER, A. (2011), "José Fernández Madrid : poeta cartagenero de la independencia," en Calvo-Stevenson, H. \& Meisel-Roca, A. (eds.), Cartagenade Indias en laindependencia. Cartagena:Banco dela República, 497-527. https://ideas.repec.org/h/bdr/bdrcap/2011-07-497-527.html

Colección de poesías arreglada por un aficionado a las musas, La Habana 1833, 2 vols. https://books.google.es/books?id=V6YK195wV5cC

https://books.google.es/books?id=768lFTcxuOwC

DE LA PEÑA JIMÉNEZ, L. A. (2018), "Exporting the Revolution: Social Mobility and Transmission of Ideas during the Independence Wars of Colombia and Greece", Paper presented at the 12th Graduate Conference in European History (GRACEH) April 26th, 2018. https://www.academia. edu/36589918/

--- $\left(2019^{\mathrm{a}}\right)$, “The Independence Processes of Greece and Colombia: Topics and Possibilities of Comparison", Global Histories 5.2 (November 2019), 134-144. https://www.academia.edu/41405383/

--- $\left(2019^{b}\right)$, "Libertad o Muerte: Las guerras post-napoleónicas en Latinoamérica y los Balcanes. El caso de Colombia y Grecia", Comunicación en VII Encuentro Internacional de Jóvenes Investigadoras e Investigadores en Historia Contemporánea - Universidad de Granada, 5-7 de septiembre de 2019. https://www.academia.edu/41718226/

DROUliA, L. (2017), Philhellénisme. Ouvrages inspirées par la Guerre de l'Indépendance Grecque, 1821-1833. Répertoire bibliographique, seconde édition revue et augmentée, Athènes: Fondation Nationale de la Recherche Scientifique.

Epistolario de Bello = Obras completas de Andrés Bello, t. 25: Epistolario I, Caracas 1982-1986.

Epistolario de Olmedo = José Joaquín de Olmedo, Epistolario, Biblioteca ecuatoriana mínima, México 1960.

FDEZ. DE CASTRO, J. A. (1942 $)$, "Un presidente neogranadino desterrado en la isla de Cuba", Rev. Univ. de La Habana 40-42 (enero-junio 1942), 7-26. --- $\left(1942^{\mathrm{b}}\right)$, "El revolucionario colombiano José Fernández Madrid y su actuación en La Habana", Rev. Univ. de La Habana 40-42 (enero-junio 1942), 27-48.

--- $\left(1942^{\mathrm{c}}\right)$, "Esfuerzos de un diplomático-poeta americano por la libertad de Cuba", Rev. Univ. de La Habana 43-45 (jul.-dic. 1942), 7-18.

GARCÍA, G. (2004), "Vertebrando la resistencia: La lucha de los negros contra el sistema esclavista, 1790-1845”, en González Ripoll, Ma D. et alii (eds.), El rumor de Haití en cuba: temor, raza, rebeldía, 1789-1844, Madrid: CSIC, 2004, 223-319. 
GÓMEZ RESTREPO, A. (1945), Historia de la literatura colombiana, t. III: Elementos de cultura desarrollados en la segunda mitad del S. XVIII, la expedición Botánica, los grandes próceres, la poesía, los poetas de Santa $\mathrm{Fe}$, apéndices, $2^{\mathrm{a}}$ ed., Bogotá.

GUTIÉRREZ ARDILA, D. (2008), "La campaña de propaganda de los Estados hispanoamericanos en Europa (1810-1830)", Anuario de historia regional $y$ de las fronteras 13.1, 9-37. https://www.academia.edu/35175775

--- (2013), "La République de Colombie face à la cause des Grecs", Hébrard, V.-Verdo, G., Las independencias hispanoamericanas. Un objeto de historia, Madrid: Casa Velázquez, 305-320.

https://www.academia.edu/28970136/

JFM, Poesías 1828 = Poesías de José Fernández Madrid, Londres 1828.

https://books.google.es/books?id=9bQGAAAAQAAJ

José Fernández Madrid y su obra en Cuba, Publicaciones del Archivo Nacional de Cuba LVI, La Habana, 1962.

JMS, La Colombiada 1853 = La Colombiada o Colón, el amor a la patria y otras poesías líricas, por el Dr. José María Salazar, Caracas 1853.

https://books.google.es/books?id=QLJbAAAAcAAJ

LATORRE BROTO, E. (2013), "Grecia como camino hacia la libertad: el filohelenismo de José María Heredia", Anales de Literatura Hispanoamericana 42, 279-296. https://www.academia.edu/40597984/

--- (2015), Griegos que el estandarte alzáis de libres. Poesía filohelénica española e hispanoamericana (1821-1843). Estudios y Textos de Erytheia, 8. Madrid: Asociación Cultural Hispano-Helénica.

https://www.academia.edu/40601880/

--- (2019), Filohelenismos hispánicos. Lo griego como referente de autorrepresentación en los discursos ideológicos de España e Hispanoamérica (1821-1824), 2 vols. Tesis doctoral. Madrid: Universidad Complutense de Madrid. https://www.academia.edu/41029829/

MARTÍNEZ SILVA, C. (1889), Biografia de don José Fernández Madrid, arreglada por Carlos Martínez Silva, Bogotá. Reeditada en Obras completas del doctor Carlos Martínez Silva (Edición dirigida por Luis Martínez Delgado), t. IV, Bogotá 1935.

MENÉNDEZ PELAYO, M. (1893), Antología de Poetas Hispano-americanos, publicada por la Real Academia Española, 4 vols., Madrid.

--- (1913), Historia de la Literatura Hispanoamericana, 2 vols., Madrid.

MIRANDA, E. (2018), "La lucha por la independencia griega en el imaginario poético cubano del XIX", Rialta Magazine. Literatura, arte y crítica cultural 19 (septiembre 2018), publicación digital

http://rialta-ed.com/la-lucha-por-la-independencia-griega-en-elimaginario-poetico-cubano-del-xix/ 
ORLANDO MELO, J.(2004), "El periodismo colombiano del s. XIX: colecciones, conservación, digitalización”, Ponencia presentada in absentia en el World Library and Information Congress: 70th IFLA General Conference and Council, 22 a 27 de agosto de 2004, Buenos Aires, Argentina. http://www.jorgeorlandomelo.com/bajar/periodismocolombiano.pdf

QUIJANO, A. (1917), “José Fernández Madrid”, Colombianos ilustres. Estudios y biografías, con carta prólogo de Luis Trigueros, t. II, Bogotá, 61-163.

SOLANO ALONSO, J. (2014), José Fernández Madrid: Ilustración, Patriotismo y Tragedia. Barranquilla: Universidad Simón Bolívar.

SUÁREZ, C. A. (1984), "La Revolución Griega de 1821. Repercusión en Buenos Aires", Revista de la Universidad de Morón 11 (noviembre 1984), 137147.

TABOADA, H. G. H. (2008), "La sombra del Oriente en la Independencia americana", en Nagy-Zekmy, S. (ed.), Moros en la costa: Orientalismo en Latinoamérica. Madrid-Frankfurt: Iberoamericana Editorial, 25-40.

TOLIAS, G. (2017), “The resilience of Philhellenism”, The Historical Review/La Revue Historique 13, 51-70. http://dx.doi.org/10.12681/hr.11556

TRIANA Y ANTORVEZA, H. (2005). "Dos colombianos en Cuba: José Fernández Madrid (1780-1830) y Félix Manuel Tanco y Bosmeniel (1796-1871)", Boletín de Historia y Antigüedades, 828, vol. xcii (marzo 2005), 65-94.

ZANOU, K. (2015), "Europe's Imaginary of Ancient and Modern Ruins: Hellenism and Philhellenism", en Kholeif, O. (ed.), Two Days After Forever: A Reader on the Choreography of Time. Berlin \& New York: Sternberg Press, 36-49. https://www.academia.edu/12070402/ 